\title{
Distribution of Brown Adipose Tissue Radiodensity in Young Adults: Implications for Cold [ ${ }^{18}$ F]FDG-PET/CT Analyses
}

\author{
Borja Martinez-Tellez $\odot,{ }^{1,2}$ Guillermo Sanchez-Delgado, ${ }^{1}$ Mariëtte R. Boon, ${ }^{2}$ \\ Patrick C. N. Rensen, ${ }^{2}$ José M. Llamas-Elvira, ${ }^{3,4}$ Jonatan R. Ruiz $^{1}$ \\ ${ }^{1}$ PROFITH "PROmoting FITness and Health through physical activity" research group. Department of Physical Education and Sport, \\ Faculty of Sport Sciences, University of Granada, Crta de Alfacar s/n, C.P. 18071, Granada, Spain \\ ${ }^{2}$ Department of Medicine, Division of Endocrinology, and Einthoven Laboratory for Experimental Vascular Medicine, Leiden University \\ Medical Center, Leiden, The Netherlands \\ ${ }^{3}$ Servicio de Medicina Nuclear, Hospital Universitario Virgen de las Nieves, Granada, Spain \\ ${ }^{4}$ Servicio de Medicina Nuclear, Instituto de Investigación Biosanitaria (ibs. GRANADA), Granada, Spain
}

\begin{abstract}
Purpose: Nowadays, 2-deoxy-2- $\left[{ }^{18} \mathrm{~F}\right]$ fluoro-D-glucose $\left(\left[{ }^{18} \mathrm{~F}\right] \mathrm{FDG}\right)$ positron emission tomography $(\mathrm{PET}) / \mathrm{X}$-ray computed tomography $(\mathrm{CT})$ is considered the best available technique to in vivo determination of human BAT volume. The most used Hounsfield unit (HU) threshold for BAT quantification is from -250 to $-50 \mathrm{HU}$. Therefore, the main objective of the present study is (i) to examine the influence of SUV and HU thresholds on BAT quantification by $\left[{ }^{18} \mathrm{~F}\right] \mathrm{FDG}-\mathrm{PET} / \mathrm{CT}$ scan, (ii) to identify the proportion of BAT which is not detected by $\left[{ }^{18} \mathrm{~F}\right] \mathrm{FDG}-\mathrm{PET} / \mathrm{CT}$ scan when limiting the range between -10 and $-50 \mathrm{HU}$, and (iii) to describe the distribution of BAT radiodensity by weight status and sex in young healthy individuals.

Procedures: We measured 125 individuals after a personalized cooling protocol with a static $\left[{ }^{18} \mathrm{~F}\right]$ FDG-PET/CT scan. We quantified BAT using different combination of threshold in every single $\mathrm{HU}$ for all participants.

Results: We observed that the SUV threshold influences BAT quantification by $\left[{ }^{18} \mathrm{~F}\right] \mathrm{FDG}$-PET/ $\mathrm{CT}$ scans more than the $\mathrm{HU}$ range. We found that the range from -50 to $-10 \mathrm{HU}$ had the highest proportion of total BAT volume (43.2\%), which represents $41.4 \%$ of the total BAT metabolic activity in our cohort. We also observed that BAT volume was not different between categories of body mass index, as well as BAT activity $\left(S U V_{\text {mean }}\right)$. In addition, BAT was less dense in women than in men, although the BAT activity $\left(S U V_{\text {mean }}\right)$ was higher in all ranges of $\mathrm{HU}$. We also observed that the radiodensity of BAT located in the cervical area was mainly in the range from -50 to $-10 \mathrm{HU}$.

Conclusion: Therefore, all future human studies using static $\left[{ }^{18}\right.$ F]FDG-PET/CT scans should include BAT in the radiodensity range from -50 to $-10 \mathrm{HU}$.
\end{abstract}

Key words: Brown fat, Hounsfield units, Standardized uptake value, Cold exposure

Electronic supplementary material The online version of this article (https:// doi.org/10.1007/s11307-019-01381-y) contains supplementary material, which is available to authorized users.

Correspondence to: Borja Martinez-Tellez; e-mail: borjammt@gmail.com

\section{Introduction}

In 2009, a set of studies demonstrated that humans have metabolically active brown adipose tissue (BAT) which is activated upon cold exposure [1-3]. Due to its energy- 
burning capacity, BAT has been postulated as a possible target to combat obesity and other comorbidities $[4,5]$. To date, the most used technique to quantify human BAT [6] is the injection of a single dose of 2-deoxy- $\left[{ }^{18} \mathrm{~F}\right]$ fluoro-Dglucose $\left(\left[{ }^{18} \mathrm{~F}\right] \mathrm{FDG}\right)$ before performing a positron emission tomography (PET) combined with X-ray computed tomography (CT) scan [7] after an acute cold exposure. Moreover, the $\left[{ }^{18} \mathrm{~F}\right] \mathrm{FDG}-\mathrm{PET} / \mathrm{CT}$ is considered the best available technique to in vivo determination of human BAT volume [8].

$\left[{ }^{18} \mathrm{~F}\right]$ FDG-PET provides information about $\left[{ }^{18} \mathrm{~F}\right]$ FDG uptake by metabolically active tissues, which is expressed as standardized uptake value (SUV). After entering into the cells, $\left[{ }^{18} \mathrm{~F}\right] \mathrm{FDG}$ is phosphorylated by hexokinase. Because it cannot be further metabolized, it becomes entrapped and can be visualized using PET [7]. However, only using $\left[{ }^{18} \mathrm{~F}\right]$ FDG-PET scan is inaccurate because the technique does not allow to identify tissues. Therefore, $\left[{ }^{18} \mathrm{~F}\right]$ FDGPET is commonly combined with $\mathrm{CT}$, which uses rotating $\mathrm{X}$-rays and tomographic reconstructions to visualize internal body structures [7]. A CT scan is able to distinguish different tissues based on the radiodensity, which is expressed as Hounsfield units (HU). The radiodensity of adipose tissue ranges from -300 to $-10 \mathrm{HU}$. The radiodensity of BAT ranges from -67 to $-10 \mathrm{HU}$ and that of WAT from -300 to $-96 \mathrm{HU}$ in mice [9-11]. U Din et al. [12] showed that human BAT radiodensity increased from thermoneutral to cold conditions and that this increase was negatively associated to whole-body adiposity markers.

To date, human BAT studies have applied more than 32 combinations of SUV and HU thresholds [13] and these combinations influence BAT volume and activity quantification by $\left[{ }^{18} \mathrm{~F}\right] \mathrm{FDG}-\mathrm{PET} / \mathrm{CT}$ scans. In 2016, a panel of experts published a set of recommendations to perform and analyze human BAT studies using this technique [6] (i.e., BARCIST 1.0), and concluded that the SUV threshold should be individualized (SUV IND) considering the participant's body composition [6]. Additionally, they suggested to use a radiodensity ranging from -190 to $-10 \mathrm{HU}$ for BAT detection and encouraged the scientific community to apply these thresholds in order to facilitate future comparisons. Nevertheless, the most used HU threshold applied in BAT quantification is from -250 to $-50 \mathrm{HU}$ [13], and several studies showed with biopsies that BAT density corresponds with the radiodensity measured with $\mathrm{HU}$ in the range from -50 to -10 [9-11]. Therefore, we do not know how much BAT is not taken into account by the most used threshold in literature. Lastly, BAT volume and activity differ between sexes, as women have higher $\left[{ }^{18} \mathrm{~F}\right]$ FDG uptake by BAT compared with men [14], which is also affected by body composition. However, whether any differences exist in terms of BAT radiodensity in men and women and between individuals with different body composition is largely unknown.
Thus, the aims of the present study are (i) to examine the influence of SUV and HU thresholds on BAT quantification by $\left[{ }^{18} \mathrm{~F}\right]$ FDG-PET/CT scan, (ii) to identify the proportion of BAT which is not detected by $\left[{ }^{18} \mathrm{~F}\right] \mathrm{FDG}-\mathrm{PET} / \mathrm{CT}$ scan when limiting the range between -10 and $-50 \mathrm{HU}$, and (iii) to describe the distribution of BAT radiodensity by weight status and sex in young healthy individuals.

\section{Materials and Methods}

\section{Participants}

This cross-sectional study was performed within the framework of the ACTIBATE project [15]. All assessments were made in Granada (Spain) during the months of October, November, and December 2015 and 2016. The study subjects were 125 young adults, 43 of whom were men (Suppl. Table 1, see Electronic Supplementary Material (ESM)) [15]. All underwent a comprehensive medical examination and reported themselves to be sedentary $(<20 \mathrm{~min}$ moderate-vigorous physical activity on $<3$ days/week), reported a stable body weight over the last 3 months $(<3 \mathrm{~kg}$ change), were not exposed to cold regularly, did not smoke, and took no medication. None suffered from cardiometabolic disease. The study was performed in accordance with current ethical guidelines (Declaration of Helsinki, as revised in 2013) and were approved by the Human Research Ethics Committee of the University of Granada (no. 924) and that of the Servicio Andaluz de Salud. All participants gave their written, informed consent to be included.

\section{Personalized Cooling Protocol}

The cooling protocol used and the quantification of the BAT volume and activity were as previously reported [14, 16]. Briefly, subjects sat in a cool room $\left(19.5-20{ }^{\circ} \mathrm{C}\right)$ wearing a water-perfused cooling vest (Polar Products Inc., Stow, OH, USA). The water temperature was reduced from $16.6{ }^{\circ} \mathrm{C}$ at $\sim 2.2{ }^{\circ} \mathrm{C}$ per 10 min until they began shivering. After $48-72 \mathrm{~h}$ had elapsed, they went to the Hospital Virgen de las Nieves, where they were again placed in a cool room $\left(19.5-20^{\circ} \mathrm{C}\right)$ and wore the same cooling vest but with the water temperature set $\sim 4{ }^{\circ} \mathrm{C}$ above their earlier shivering threshold test result for $2 \mathrm{~h}$. After the first hour, the subjects received an injection of $\left[{ }^{18} \mathrm{~F}\right]$ FDG $(\sim$ $185 \mathrm{MBq}$ ) and the water temperature was increased by $1{ }^{\circ} \mathrm{C}$ to avoid visually detectable shivering. One hour later, they were subjected to PET/CT using a Siemens Biograph 16 PET/CT scanner (Siemens, Erlangen, Germany), scanning two BEDs from the atlas vertebra to thoracic vertebra 6 (approximately). 


\section{PET/CT Analysis}

The PET/CT images were analyzed using the Beth Israel plugin for FIJI [1] software (by BMT) under the supervision of a nuclear medicine physician (JMLL) [17]. The regions of interest (ROIs) were semiautomatically outlined from atlas vertebrae (Cervical 1) to thoracic vertebrae 4 using a 3D Axial technique [18]. We established the cervical region from atlas vertebrae to $\mathrm{C} 7$ (Fig. 4a) and thoracic region from $\mathrm{C} 7$ to Th4 (Fig. $4 b)$. SUV was calculated as $\left[{ }^{18} \mathrm{~F}\right]$ FDG uptake $((\mathrm{kBq} / \mathrm{ml}) /$ (injected dose $[\mathrm{kBq}] /$ patient weight $[\mathrm{g}])$ ). We defined BAT volume, $\mathrm{SUV}_{\text {mean }}$, and $\mathrm{SUV}_{\text {peak }}$ following BARCIST 1.0 criteria (SUV IND threshold $=(1.2 /($ lean body mass/body mass))), and we defined BAT metabolic activity as the product of BAT volume and $\mathrm{SUV}_{\text {mean }}$ [6]. We downloaded a csv file with the single value of $\mathrm{HU}$ and SUV for every active pixel inside the ROIs from the Beth Israel plugin for FIJI software. Later, we quantified BAT volume and activity in every single range of $\mathrm{HU}$ (from 0 to -1 , from -1 to -2 , and so on until -300 ). Once we identified all the pixels located in the range of HU, we applied different SUV and HU thresholds. Firstly, we used different SUV thresholds $(1.5,2.0,2.5$, 3.0 , and IND) with a fixed range of $\mathrm{HU}(-10,-300)$ for quantification of BAT volume and activity $\left(\mathrm{SUV}_{\text {mean }}\right)$. Secondly, we used a fixed SUV threshold (SUV IND) but we modified the ranges of HU $(-190,-10 ;-180,-$ $10 ;-190,-150$; and $-250,-50)$ and we quantified again BAT volume and activity for every single combination. We established as the reference BAT volume and activity the ones calculated with SUV IND as recommended by the BARCIST 1.0 criteria [6] and the radiodensity range of adipose tissue (from -300 to -10 $\mathrm{HU})$. We then averaged the number of pixels in every range of radiodensity to obtain the average of radiodensity. The PET/CT scans were visually examined to classify participants as PET+ (BAT volume $\geq 5 \mathrm{ml}$ and $\left[{ }^{18} \mathrm{~F}\right]$ FDG uptake clearly in the well-known regions) or PET - (BAT volume $<5 \mathrm{ml}$ and none $\left[{ }^{18} \mathrm{~F}\right]$ FDG uptake in these regions) $[14,19]$.

\section{Body Composition}

Lean body mass (LBM) and fat body mass were determined using a Hologic Discovery Wi dual energy X-ray absorptiometer (DXA) (Hologic, MA, USA). Body weight and height were measured using a SECA model 799 electronic column scale and stadiometer (SECA, Hamburg, Germany). Body mass index (BMI) and lean mass index (LMI) were calculated as body weight/LBM divided by height squared. The participants were categorized as underweight $\left(\mathrm{BMI} \leq 18.5 \mathrm{~kg} / \mathrm{m}^{2}\right)$, normal weight $(\mathrm{BMI} \geq 18.5$ and $<25 \mathrm{~kg} / \mathrm{m}^{2}$ ), overweight $\left(\mathrm{BMI} \geq 25\right.$ and $\left.<30 \mathrm{~kg} / \mathrm{m}^{2}\right)$, and obese (BMI $\left.\geq 30 \mathrm{~kg} / \mathrm{m}^{2}\right)$ [20].

\section{Statistical Analysis}

The descriptive characteristics of the study participants are presented as mean and standard deviation (SD) unless otherwise stated. To examine the influence of SUV and HU thresholds on the quantification of BAT, we conducted linear regression analysis with BAT volume and activity quantified by SUV IND, HU -10 to -300 as independent variable and BAT volume and activity quantified by different combination of $\mathrm{HU}$ and SUV thresholds as dependent variables. The analyses were conducted in 16 separate regression models. We performed paired $t$ test for the comparison between the absolute values of BAT calculated by the reference threshold $v s$. the different combination (Suppl. Table 2, see ESM). We selected the range of -250 to -50 because it is the most used in literature [8]; then, we used the range of -190 to -10 because it was proposed by the BARCIST criteria [6]. Lastly, we used the second most used threshold in literature -180 to -10 [8] and then the combination -190 to -50 . With these 4 thresholds, we can study how modifying the upper or lower thresholds of the HU could modify the measurement of BAT. To identify the proportion of BAT which is detected by $\left[{ }^{18} \mathrm{~F}\right] \mathrm{FDG}-\mathrm{PET} / \mathrm{CT}$ scan in the range between -50 and $10 \mathrm{HU}$, we quantified the amount of BAT volume for every single range of $\mathrm{HU}$. Later, we calculated the percentage of BAT volume and metabolic activity for every range of $10 \mathrm{HU}$ with respect to the total amount measured by the reference criteria (SUV IND; HU - 300, -10). To study the interaction effect of the HU ranges with BMI or sex on the adipose tissue (BAT and WAT) volume, as well as on BAT volume and activity, we conducted a two-way analysis of variance (ANOVA) with repeated measurements. We introduced the amount of BAT calculated every $10 \mathrm{HU}$ (for instance, from 0 to 10 , from -11 to $-20 \mathrm{HU}$, and so on; 30 levels) as within-subject factor and weight status (underweight, normal weight, overweight, obese) or sex as betweensubject factors. Moreover, we calculated the mean radiodensity with the different combination of thresholds selected for the regression analyses. All analyses were performed using the IBM SPSS Statistics for Windows version 22.0 (IBM Corp, Armonk, NY, USA), and the level of significance was set to $P<0.05$.

\section{Results}

\section{SUV Influences BAT Outcomes More Than HU Range}

First, we confirmed that $\left[{ }^{18} \mathrm{~F}\right]$ FDG uptake by BAT significantly changed when both SUV and HU were modified in comparison with the reference criteria (SUV IND; HU $-300,-10$ ) in the whole sample (Suppl. Fig. 1, see ESM) [13]. Next, we examined the association of BAT 
volume quantified by SUV IND, HU -300 to -10 with BAT volume using a fixed SUV IND threshold but modifying the HU thresholds (HU $-190,-10$ (Fig. 1a); $\mathrm{HU}-180,-10$ (Fig. 1b); HU $-190,-50$ (Fig. 1c); and HU $-250,-50$ (Fig. 1d)). We repeated the same analysis using a fixed HU range $(-300,-10)$ but modifying the SUV threshold (SUV 1.5 (Fig. 1e), 2.0 (Fig. 1f), 2.5 (Fig. 1g), and 3.0 (Fig. 1h)). In all regressions, we found positive and significant associations (all $P \leq 0.001$ ). However, we found that when modifying the $\mathrm{HU}$ thresholds, the explained variance $\left(R^{2}\right)$ varied from 0.948 to 1.000 , whereas modifying the SUV resulted in $R^{2}$ values between 0.883 and 0.938 in comparison with BAT volume quantification by the reference method. Moreover, we found that the standardized beta of these linear regressions was lower when we modified SUV thresholds in comparison with HU thresholds (Fig. 1i). Similar results were found in terms of BAT activity
$\left(\mathrm{SUV}_{\text {mean }}\right)$ (Suppl. Fig. 2, see ESM). It should be noted that we only found a perfect correlation between BAT quantified using the criteria of SUV IND, HU -300 to -10 and BAT quantified by the BARCIST proposal (SUV IND; HU - 190, -10 ) and with SUV IND, HU -180 to -10 , both for BAT volume and activity $\left(\mathrm{B}=1.000 ; R^{2}=1.000 ; P \leq 0.001\right.$, Fig. $1 \mathrm{a}$ and $\mathrm{b}$ and Suppl. Fig. $2 \mathrm{a}$ and $\mathrm{b}$, see ESM). Furthermore, we performed further comparisons between thresholds in absolute values (Suppl. Table 2, see ESM).

Similarly, the mean radiodensity differed when the SUV or the HU thresholds changed (Suppl. Fig. 3a and $b$, see ESM). The differences were especially higher when the HU threshold excluded the range from -50 to -10 HU. Moreover, we showed that the association between the mean radiodensity and BMI was affected by excluding the range from -50 to -10 HU (Suppl. Fig. $3 c$ and d, see ESM). a

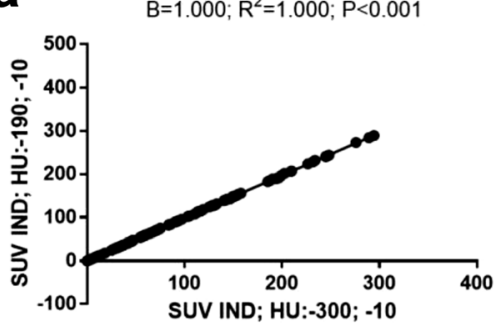

d

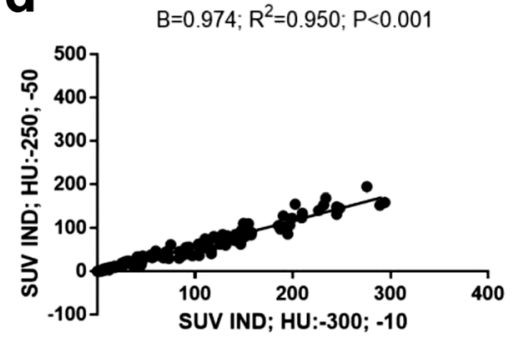

g

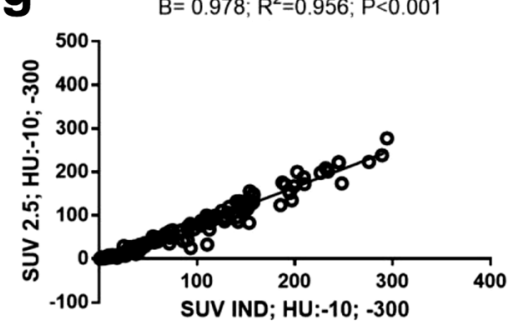

b

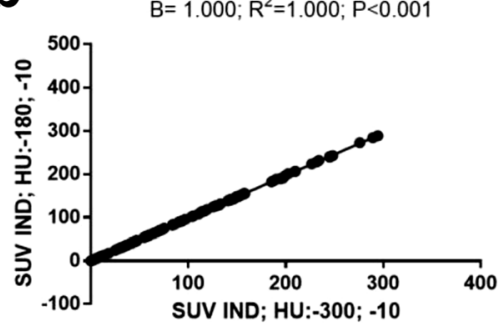

\section{e}

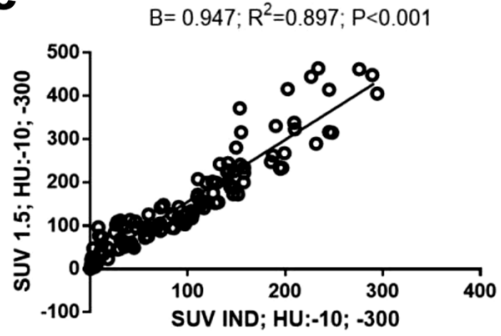

h

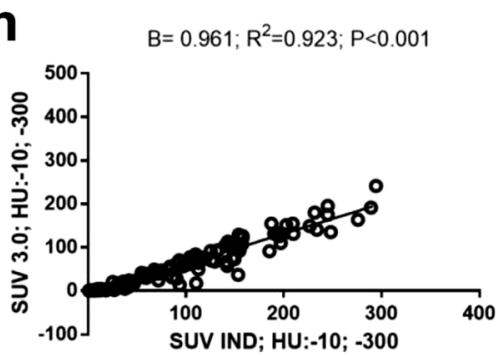

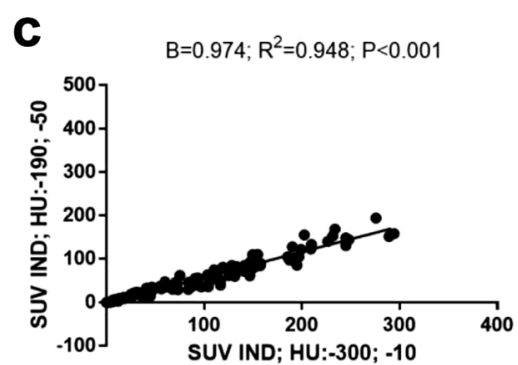

f
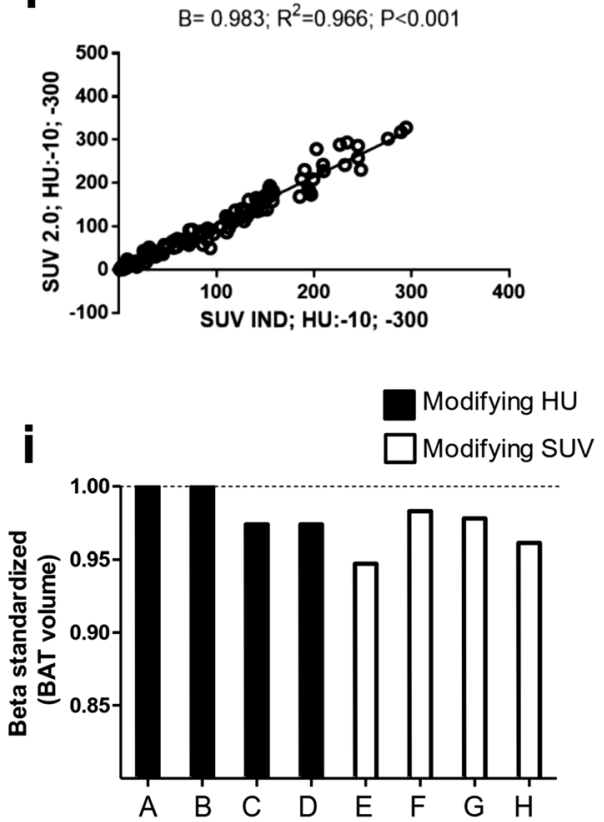

Fig. 1. Associations of brown adipose tissue (BAT) volume quantified by the individualized standardized uptake value (SUV IND) threshold and a range of Hounsfield units (HU) from - 10 to -300 , with BAT volume measured by the SUV IND threshold by applying different ranges of $\mathrm{HU}(\mathbf{a}-10,-190 ; \mathbf{b}-10,-180$; $\mathbf{c}-50,-190$; and d $-50,-250)$ in 125 participants. We repeated the same associations but modifying the SUV threshold instead of the HU threshold. We estimated BAT volume applying different SUVs (e 1.5, f 2.0, $\mathbf{g}$ 2.5, and $\mathbf{h}$ 3.0). i We represented all the $r$ of Pearson of the correlation in one plot. B, beta standardized; $R^{2}$ : explained variance. 


\section{Most BAT Presents a Radiodensity Between - 100 and $-10 \mathrm{HU}$}

We next studied in which radiodensity range most BAT is present. To this end, we investigated the whole range of HU that is supposed to contain adipose tissue (both BAT and WAT; from -300 to $-10 \mathrm{HU}$ ) and we applied the SUV IND threshold. We observed that BAT (as volume) was mostly present in the range from -150 to $-10 \mathrm{HU}$ (Fig. 2a and d), representing the $96.8 \%$ of the total BAT volume. We also calculated BAT activity $\left(\mathrm{SUV}_{\text {mean }}\right)$ and BAT metabolic activity every $10 \mathrm{HU}$, finding similar results (Fig. $2 b$ and c) in the range from -150 to -10 HU, which represent the $98.0 \%$ of the total metabolic activity of $\left[{ }^{18} \mathrm{~F}\right]$ FDG uptake by BAT. Based on these data, the $43.2 \%$ of BAT volume was contained in the range -50 to $-10 \mathrm{HU}$, and the $42.6 \%$ of BAT volume was contained in the range -100 to $-51 \mathrm{HU}$ (Fig. 2d). In addition, the range -50 to $-10 \mathrm{HU}$ contained $41.4 \%$ of total metabolic activity of BAT and the range -100 to $-50 \mathrm{HU}$ contained $45.2 \%$ (Fig. 2e). At $\mathrm{HU} \leq-150$, only $5.2 \%$ of the total amount of BAT was present, with low $\left[{ }^{18} \mathrm{~F}\right]$ FDG uptake by BAT $(0.1 \%$ of total) (Fig. 2e).

\section{$B M I$ and Sex Affect the Distribution of BAT Radiodensity}

We next calculated the percentage of adipose tissue (without applying a SUV threshold, thus including both BAT and WAT) within the HU ranges, dividing by different categories of BMI (i.e., studying interaction). We observed that overweight and obese participants had a higher proportion of adipose tissue in the $\mathrm{HU}$ range from -300 to $-75 \mathrm{HU}$, whereas underweight and normal weight participants had a higher proportion of adipose tissue with a higher radiodensity (Fig. 3a; $P$ for $\mathrm{HU} \times \mathrm{BMI} \leq 0.001$ ). When we applied a SUV IND threshold for quantifying BAT, the interaction disappeared (Fig. 3b; $P$ for $\mathrm{HU} \times \mathrm{BMI}=0.109$ ). We also studied BAT activity $\left(\mathrm{SUV}_{\text {mean }}\right)$, and we did not observe interaction (Fig. $3 \mathrm{c} ; P$ for $\mathrm{HU} \times \mathrm{BMI}=0.352$ ). In the whole sample, we were unable to detect glucose uptake in BAT depots in 21 participants (PET-) (Table S1). PETparticipants had the same adipose tissue distribution than PET+ participants (Suppl. Fig. 4a, see ESM), but a different BAT radiodensity distribution (Suppl. Fig. $4 \mathrm{~b} ; P$ for $\mathrm{HU} \times$ PET $<0.001$, see ESM). We therefore repeated the analyses excluding PET- scans and observed that the interaction between adipose tissue radiodensity remained (Suppl. Fig. 5a; $P$ for $\mathrm{HU} \times \mathrm{BMI} \leq 0.001$, see $\mathrm{ESM}$ ). Moreover, after excluding PET-, there were interactions in the distribution of BAT radiodensity between categories of BMI (Suppl. Fig. 5b; $P$ for $\mathrm{HU} \times \mathrm{BMI}=0.004$, see $\mathrm{ESM}$ ). Overweight and obese participants had a higher proportion of BAT located in less denser ranges in comparison with normal weight and underweight participants, who had a higher proportion of BAT radiodensity in a denser range (from -10 to -50 ). There were no differences in terms of BAT activity $\left(\mathrm{SUV}_{\text {mean }}\right)($ Suppl. Fig. 5 c; $P$ for $\mathrm{HU} \times \mathrm{BMI}=$ 0.126 , see ESM).

Next, we studied whether sex affects BAT radiodensity (Fig. 3d-f). Women had a higher percentage of adipose tissue in the value of radiodensity between -300 and -100 HU than men, who had higher percentage of adipose tissue in a denser range (from -50 to $-10 \mathrm{HU}$ ) (Fig. $3 \mathrm{~d}$; $P$ for $\mathrm{HU}$ $\times \operatorname{sex} \leq 0.001)$. In addition, when we applied the SUV IND
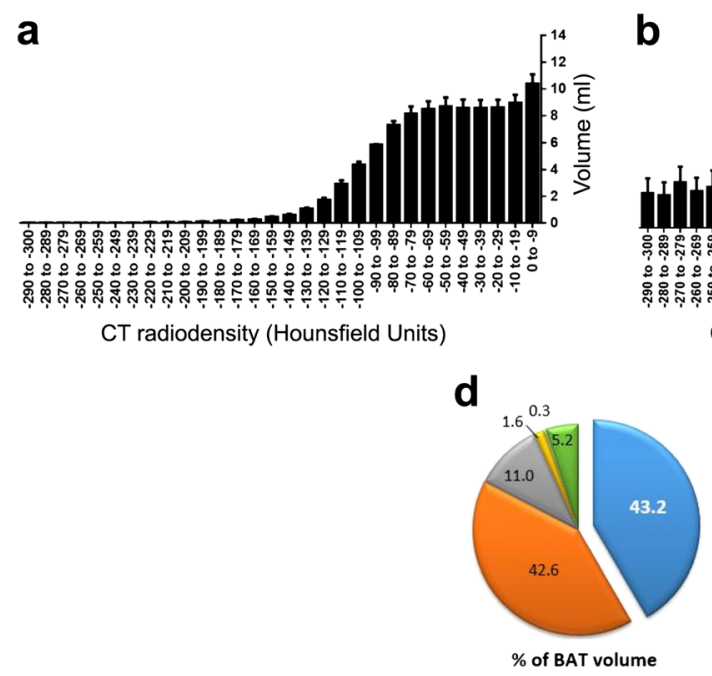
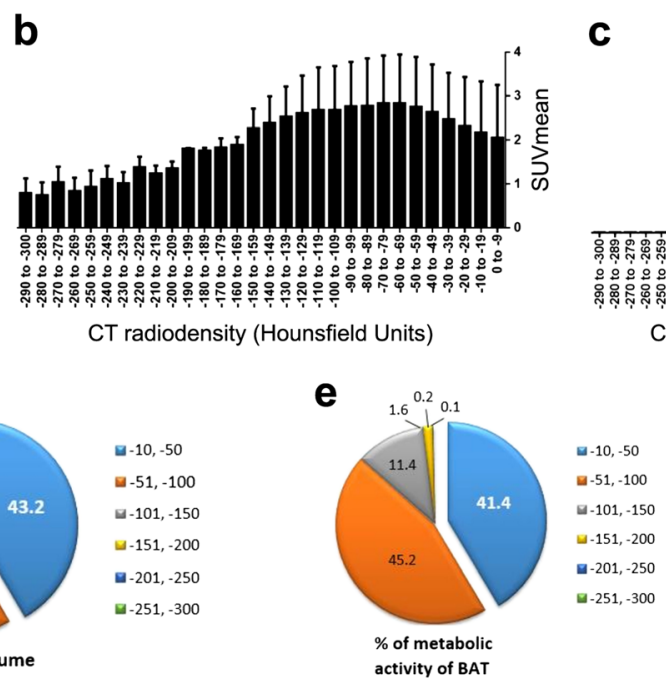

Fig. 2. Distribution of brown adipose tissue (BAT) by ranges of 10 Hounsfield units (HU) where adipose tissue is known to be present (from - 10 to - 300) in 125 participants. BAT was calculated using individualized standardized uptake value (SUV) threshold. a BAT volume. b BAT activity (SUV mean). c BAT metabolic activity. d Percentage of BAT volume in different HU ranges. e Percentage of BAT metabolic activity in different HU ranges. Data are represented as mean and standard deviation, otherwise indicated. 


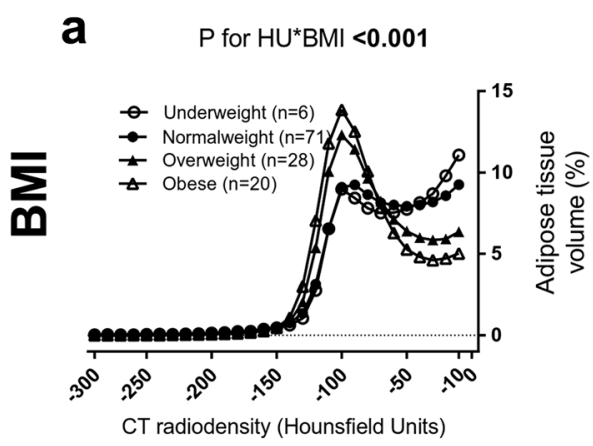

d

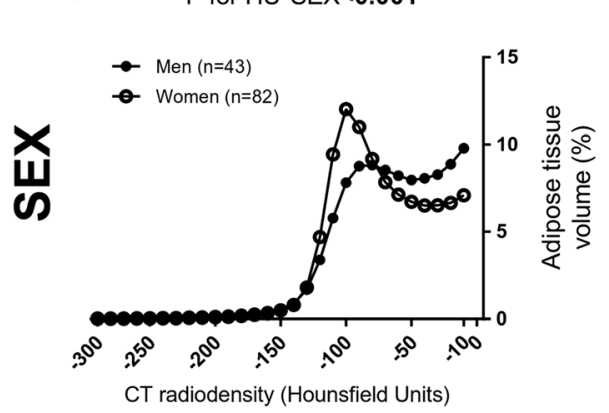

b

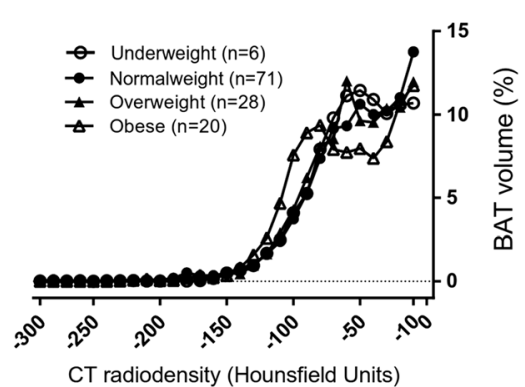

e

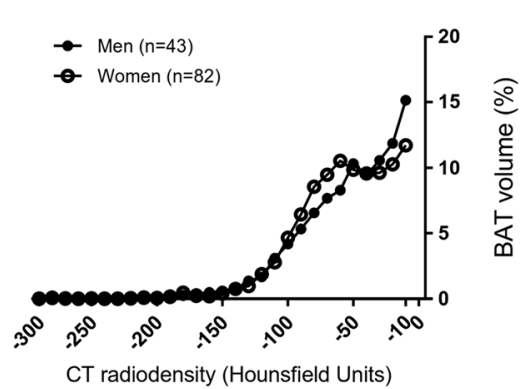

C $\quad \mathrm{P}$ for $\mathrm{HU}^{*} \mathrm{BMI}=0.352$

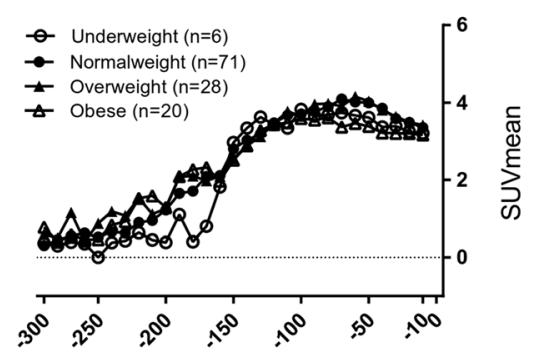

CT radiodensity (Hounsfield Units)

f

$P$ for $H U^{*} \mathrm{SEX}<0.001$

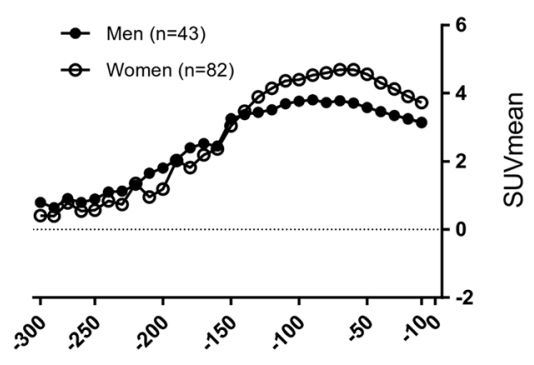

CT radiodensity (Hounsfield Units)

Fig. 3. Distribution of adipose tissue, brown adipose tissue (BAT) volume, and BAT activity by body mass index (BMI) and sex. a Distribution of fat volume without applying standardized uptake value (SUV) threshold by BMl categories. $\mathbf{d}$ The same as in a but by sex. $\mathbf{b}$ Patterns of BAT volume after applying the individualized SUV threshold. $\mathbf{e}$ The same as in $\mathbf{d}$ but by sex. $\mathbf{c}$ Patterns of BAT activity after applying the individualized SUV threshold. $\mathbf{f}$ The same as in $\mathbf{c}$ but by sex. $\mathbf{a}, \mathbf{b}, \mathbf{d}$, and $\mathbf{e}$ are represented as percentage of the individual total volume. $P$ for trend obtained from a bifactorial analysis of variance.

threshold, we observed that men had a higher proportion of BAT volume in comparison with women in denser ranges of HU (Fig. 3e; $P$ for $\mathrm{HU} \times$ sex $=0.023$ ). However, women showed higher proportion of BAT activity $\left(\mathrm{SUV}_{\text {mean }}\right)$ in the whole range of $\mathrm{HU}$ than men (Fig. 3f; $P$ for $\mathrm{HU} \times$ sex $\leq$ 0.001). All these results persisted when BMI was introduced as co-variable (data not shown).

\section{Cervical BAT Has Higher Radiodensity Than Thoracic BAT}

We next analyzed whether BAT radiodensity differed between the two most common human BAT depots, cervical vs. thoracic (supraclavicular, mediastinal, and paravertebral) (Fig. 4a and b) [18]. We observed that BAT volume of the cervical area was denser in comparison with thoracic BAT (Fig. $4 \mathrm{c} ; P$ for $\mathrm{HU} \times$ area $\leq 0.001$ ). These results persisted when we excluded PET - participants (Fig. $4 \mathrm{~d}$; $P$ for $\mathrm{HU} \times$ area $\leq 0.001)$ and when the analyses were adjusted by BMI or sex (data not shown).

\section{Discussion}

The present study shows that the SUV threshold influences BAT quantification by $\left[{ }^{18} \mathrm{~F}\right] \mathrm{FDG}-\mathrm{PET} / \mathrm{CT}$ scans more than the HU range. Furthermore, we observed that the range from -50 to $-10 \mathrm{HU}$ had the highest proportion of total human
BAT volume (43.2 \%), which represents $41.4 \%$ of the total BAT metabolic activity in our cohort. Moreover, excluding the HU range between -50 and -10 affected also the mean value of radiodensity. We furthermore showed that BAT volume was not different between categories of BMI, as well as BAT activity ( $\left.\mathrm{SUV}_{\text {mean }}\right)$. In addition, BAT was less dense in women than in men, although the BAT activity $\left(\mathrm{SUV}_{\text {mean }}\right)$ was higher in all ranges of HU. Therefore, all future human studies using static $\left[{ }^{18} \mathrm{~F}\right]$ FDG-PET/CT scans should include BAT in the radiodensity range from -50 to $-10 \mathrm{HU}$. This study also shows that the radiodensity of BAT located in the cervical area was mainly in the range from -50 to $-10 \mathrm{HU}$, yet further studies are needed to confirm these results.

\section{Hounsfield Unit Range for Assessing BAT}

Recently, a consortium [6] suggested using the SUV IND because $\left[{ }^{18} \mathrm{~F}\right]$ FDG uptake is not equally distributed between tissues. Our results do support this idea, because modifying the SUV thresholds decreased the explained variance and the standardized beta of the linear regressions in comparison with modifying the HU thresholds for BAT outcomes. In addition, BARCIST 1.0 proposed a range for the BAT radiodensity (from -190 to $-10 \mathrm{HU}$ ) [6], which perfectly correlated with a criteria with bigger range of density $(-300$, $-10 \mathrm{HU}$ ). Furthermore, we found that the $43.2 \%$ of the total 


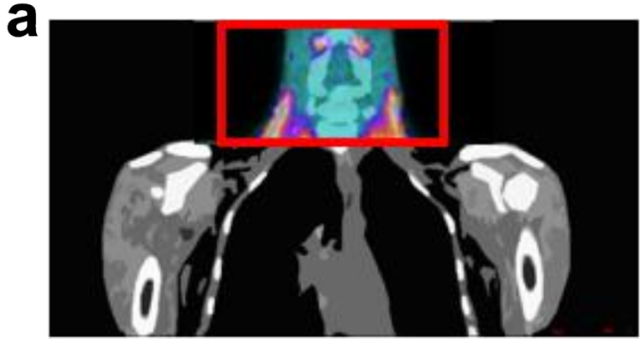

C All $(n=125)$

$P$ for $\mathrm{HU}^{*}$ Area $<0.001$

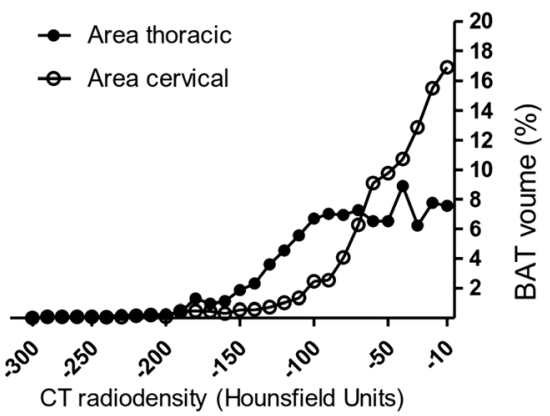

b

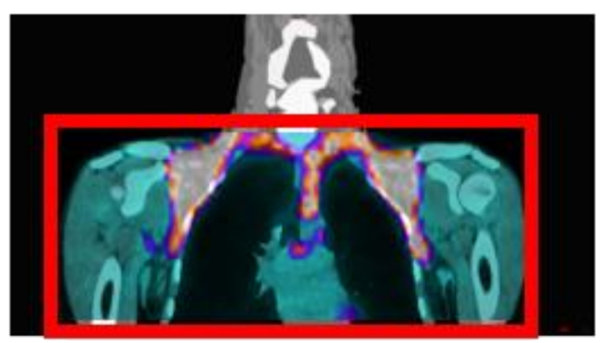

PET+ $(n=104)$

$\mathrm{P}$ for $\mathrm{HU}^{*}$ Area $<\mathbf{0 . 0 0 1}$

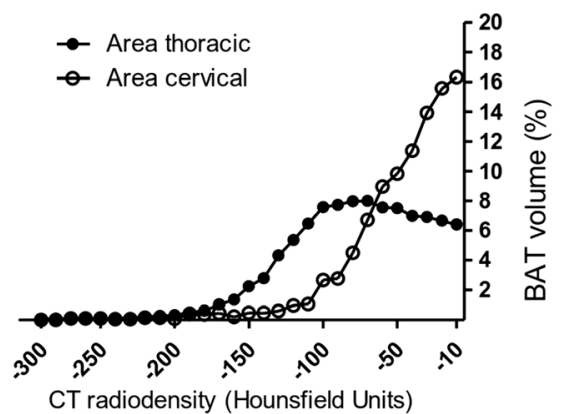

Fig. 4. Distribution of brown adipose tissue (BAT) radiodensity across ranges of 10 Hounsfield unit (HU) by anatomic location (cervical vs. thoracic). a Cervical region selected: from atlas cervical to cervical vertebrae 7. b Thoracic region selected: from cervical vertebrae 7 to thoracic vertebrae 4. c Percentage of BAT volume with respect to the total amount of BAT volume in the cervical area, in every range of $10 \mathrm{HU}$ in the whole sample. d Percentage of BAT volume with respect to the total amount of BAT volume in the thoracic area, in every range of $10 \mathrm{HU}$ in PET+ participants. Data are represented as mean.

amount of BAT is present in the range from -50 to -10 HU. Obviously, the most used HU threshold in literature ($250,-50 \mathrm{HU})$ is excluding this amount of BAT. Thus, we reason that these studies missed an important portion of the human BAT, mostly cervical BAT.

On the other hand, U Din et al. [12] recently showed that the mean BAT radiodensity is inversely related to makers of adiposity (e.g., BMI and waist circumference). However, they quantified the mean radiodensity with the most used thresholds in literature (SUV 2.0; HU $-50,-250$ ). Here, we showed that the results of the associations between the mean BAT radiodensity with markers of adiposity are possibly influenced by the fact of including the range from -10 to $-50 \mathrm{HU}$, more than including the range from -190 to $-250 \mathrm{HU}$ or -190 to 300 HU. Moreover, Aubrey et al. [21] showed that skeletal muscle radiodensity could be found in the range from -29 to $150 \mathrm{HU}$ based on thermoneutral CT scans; however, there is no evidence whether this negative $\mathrm{HU}(\sim-29 \mathrm{HU})$ is positive after a cold exposure, although U Din et al. [12] showed that skeletal muscle radiodensity increased after a cold exposure. In addition, Blondin et al. [22] observed that deep skeletal muscles are quite active and had a high $\left[{ }^{18} \mathrm{~F}\right]$ FDG uptake after a cold exposure. We observed that the adipose tissue in the neck area (where the deep muscles are located) was denser in comparison with the thoracic adipose tissue. Based on that, we cannot assure that the range from -50 to $-10 \mathrm{HU}$ is excluding all the skeletal muscle activity, and therefore, future studies need to be very careful when selecting the range of $\mathrm{HU}$ for BAT quantification, because it matters.

\section{Differences in the Distribution of BAT Radiodensity by BMI and Sex}

Some white adipose tissue (WAT) has the possibility to transdifferentiate in beige tissue by a process commonly named as browning [23]. During this process, the number of mitochondria, as well as the levels of uncoupling protein 1 (UCP1), increases in WAT [24]. Nothing is known about the radiodensity of beige tissue or whether radiodensity measured by CT scan is able to distinguish between brown, white, and beige tissues. Several authors have postulated that WAT and BAT could be overlapped in terms of HU, and BARCIST [6] suggested that applying a SUV IND threshold, somehow, we are able to distinguish both tissues, although it is unclear. Based on mice studies, it can be postulated that radiodensity of beige tissues should be intermediate between BAT and WAT "neither BAT, nor WAT, but something in between," whereas Carpentier et al. [8] suggested that the differentiation between BAT vs. WAT should be done in terms of the metabolic activity of the tissues. However, further studies are needed to verify this in humans because both options are feasible.

In 2012, Cypess et al. [25] performed BAT biopsies from the cervical area in humans finding that this tissue was 
predominantly beige. Furthermore, some studies postulated that humans may not have classical BAT as mice do. These studies hypothesized that supraclavicular human BAT is predominantly brite/beige adipose tissue surrounded by WAT. Moreover, the observed differences in BAT radiodensity between the cervical and thoracic areas could be based on the fact that BAT of the cervical area seems to be predominantly beige [26]. Nevertheless, the BAT within the thoracic area could be wrapped by WAT, as other studies have postulated [27, 28]. This could explain the higher proportion of less dense tissue observed in comparison with cervical BAT. The possible fact that BAT is wrapped by WAT in the thoracic area might also explain why overweight and obese individuals have a higher proportion of adipose tissue (including BAT and WAT) and slightly higher levels of BAT (only when PETscans were excluded) in lower ranges of radiodensity compared with underweight and normal weight individuals, although it should be confirmed. It should be noted that the metabolic activity of BAT upon a cold exposure was not different between categories of BMI.

We observed that women had less dense adipose tissues, as well as less dense BAT in comparison with men, independently of the BMI. This could mean that differences in adipose tissue radiodensity might be a sex feature more than a weight status feature. Moreover, we observed that women had a higher $\left[{ }^{18} \mathrm{~F}\right]$ FDG uptake by BAT in the whole range of HU. Therefore, having a higher BAT radiodensity does not necessarily mean higher $\left[{ }^{18} \mathrm{~F}\right]$ FDG uptake by this tissue; as in the present study, we found the opposite in women. Further studies are needed to characterize the differences in radiodensity of adipose tissues between females and males.

The results of the present study should be interpreted with caution because we only included the upper part of the body where BAT is mainly located [18]; thus, including other BAT depots (such as suprarenal depots) could modify the results. It is well known that brown adipocytes not only consume glucose, but also (triglyceride-derived) fatty acids [29]. Of note is also that our study is based on a glucose analogue, and the BAT glucose uptake could be affected by the level of insulin resistance or age. Therefore, it will be helpful to study the BAT radiodensity with other tracers such as $\left[{ }^{18} \mathrm{~F}\right]$ fluoro-6thia-heptadecanoic acid or $\left[{ }^{11} \mathrm{C}\right]$ acetate. Moreover, we used a personalized cooling protocol based on the subjective perception of shivering of the participants. Recently, Gordon et al. [30] postulated that a personalized cooling protocol could be created based on the skin temperature measurement (an objective quantification) in lean subjects; therefore, further studies using this technique for BAT quantification could be of interest in the field.

\section{Conclusions}

We showed that SUV thresholds should determine BAT quantification more than $\mathrm{HU}$ thresholds. We showed that it should be interesting to include the range from -10 to -50 $\mathrm{HU}$ because it contains a huge proportion of the total BAT volume (43.2\%), which represented $41.4 \%$ of the total BAT metabolic activity in our study. We observed that the distribution of BAT radiodensity was not different between categories of BMI but was different between sexes. All future human studies using static $\left[{ }^{18} \mathrm{~F}\right] \mathrm{FDG}-\mathrm{PET} / \mathrm{CT}$ scans should include the range from -50 to $-10 \mathrm{HU}$, which mainly represent BAT located in the cervical area.

Acknowledgments. We are grateful to Ms. Carmen Sainz-Quinn for assistance with the English language.

Author Contributions. B.M.T., G.S.D., and J.R.R. conceived and designed the research, performed the experiments, analyzed the data, interpreted the results, prepared the figures, and drafted the manuscript. All authors critically revised the manuscript and approved the final version.FundingThis study was supported by the Spanish Ministry of Economy and Competitiveness, Fondo de Investigación Sanitaria del Instituto de Salud Carlos III (PI13/01393) and Retos de la Sociedad (DEP2016-79512-R), Fondos Estructurales de la Unión Europea (FEDER), by the Spanish Ministry of Education (FPU 13/04365), by the Fundación Iberoamericana de Nutrición (FINUT), the Redes Temáticas de Investigación Cooperativa RETIC (Red SAMID RD16/0022), the AstraZeneca HealthCare Foundation, the University of Granada Plan Propio de Investigación 2016 - Excellence actions: Unit of Excellence on Exercise and Health (UCEES) - and Plan Propio de Investigación 2018 - Programa Contratos-Puente, and the Junta de Andalucía, Consejería de Conocimiento, Investigación y Universidades (FEDER, ref. SOMM17/6107/UGR). This study is part of a Ph.D. Thesis conducted in the Biomedicine Doctoral Studies of the University of Granada, Spain.

\section{Compliance with Ethical Standards}

\section{Conflict of Interest}

The authors declare that they have no conflicts of interest.

\section{Ethical Approval}

All procedures performed in studies involving humans participants were in accordance with the ethical standards of the institutional and/or national research committee and with the principles of the 1964 Declaration of Helsinki and its later amendments or comparable ethical standards. The study was approved by the institutional ethics committee.

\section{Informed Consent}

Informed consent was obtained from all individual participants included in the study.

Open Access This article is distributed under the terms of the Creative Commons Attribution 4.0 International License (http:// creativecommons.org/licenses/by/4.0/), which permits unrestricted use, distribution, and reproduction in any medium, provided you give appropriate credit to the original author(s) and the source, provide a link to the Creative Commons license, and indicate if changes were made.

\section{References}

1. Cypess AM, Lehman S, Williams G, Tal I, Rodman D, Goldfine AB, Kuo FC, Palmer EL, Tseng YH, Doria A, Kolodny GM, Kahn CR (2009) Identification and importance of brown adipose tissue in adult humans. N Engl J Med 360:1509-1517

2. Virtanen KA, Lidell ME, Orava J, Heglind M, Westergren R, Niemi T, Taittonen M, Laine J, Savisto NJ, Enerbäck S, Nuutila P (2009) Functional brown adipose tissue in healthy adults. N Engl J Med $360: 1518-1525$ 
3. van Marken Lichtenbelt WD, Vanhommerig JW, Smulders NM, Drossaerts JMAFL, Kemerink GJ, Bouvy ND, Schrauwen P, Teule GJJ (2009) Cold-activated brown adipose tissue in healthy men. N Engl J Med 360:1500-1508

4. Hanssen MJW, Wierts R, Hoeks J, Gemmink A, Brans B, Mottaghy FM, Schrauwen P, van Marken Lichtenbelt WD (2015) Glucose uptake in human brown adipose tissue is impaired upon fastinginduced insulin resistance. Diabetologia 58:586-595

5. Lee P, Smith S, Linderman J et al (2014) Temperature-acclimated brown adipose tissue modulates insulin sensitivity in humans. Diabetes 177:1-59

6. Chen KY, Cypess AM, Laughlin MR, Haft CR, Hu HH, Bredella MA, Enerbäck S, Kinahan PE, Lichtenbelt WM, Lin FI, Sunderland JJ, Virtanen KA, Wahl RL (2016) Brown Adipose Reporting Criteria in Imaging STudies (BARCIST 1.0): recommendations for standardized FDG-PET/CT experiments in humans. Cell Metab 24:210-222

7. Chondronikola M, Beeman S, Wahl RL (2017) Non-invasive methods for the assessment of brown adipose tissue in humans. J Physiol 596:363-378

8. Carpentier AC, Blondin DP, Virtanen KA et al (2018) Brown adipose tissue energy metabolism in humans. Front Endocrinol (Lausanne) 9:1-21

9. Baba S, Jacene HA, Engles JM et al (2010) CT Hounsfield units of brown adipose tissue increase with activation : preclinical and clinical studies. J Nucl Med 51:246-250

10. Ahmadi N, Hajsadeghi F, Conneely M, Mingos M, Arora R, Budoff M, Ebrahimi R (2013) Accurate detection of metabolically active "brown" and "white" adipose tissues with computed tomography. Acad Radiol 20:1443-1447

11. $\mathrm{Hu} \mathrm{HH}$, Chung SA, Nayak KS et al (2012) Differential computed tomographic attenuation of metabolically active and inactive adipose tissues: preliminary findings. J Comput Assist Tomogr 35:65-71

12. U Din M, Raiko J, Saari T, Saunavaara V, Kudomi N, Solin O, Parkkola R, Nuutila P, Virtanen KA (2017) Human brown fat radiodensity indicates underlying tissue composition and systemic metabolic health. J Clin Endocrinol Metab 102:2258-2267

13. Martinez-Tellez B, Nahon KJ, Sanchez-Delgado G, Abreu-Vieira G, Llamas-Elvira JM, van Velden FHP, Pereira Arias-Bouda LM, Rensen PCN, Boon MR, Ruiz JR (2018) The impact of using BARCIST 1.0 criteria on quantification of BAT volume and activity in three independent cohorts of adults. Sci Rep 8:8567. https://doi.org/ $10.1038 / \mathrm{s} 41598-018-26878-4$

14. Martinez-Tellez B, Sanchez-Delgado G, Garcia-Rivero Y et al (2017) A new personalized cooling protocol to activate brown adipose tissue in young adults. Front Physiol 8:1-10

15. Sanchez-Delgado G, Martinez-Tellez B, Olza J, Aguilera CM, Labayen I, Ortega FB, Chillon P, Fernandez-Reguera C, Alcantara JMA, Martinez-Avila WD, Muñoz-Hernandez V, Acosta FM, PradosRuiz J, Amaro-Gahete FJ, Hidalgo-Garcia L, Rodriguez L, Ruiz YAK, Ramirez-Navarro A, Muros-de Fuentes MA, García-Rivero Y, Sanchez-Sanchez R, de Dios Beas Jimenez J, de Teresa C, Navarrete S, Lozano R, Brea-Gomez E, Rubio-Lopez J, Ruiz MR, Cano-Nieto A, Llamas-Elvira JM, Jimenez Rios JA, Gil A, Ruiz JR (2015) Activating brown adipose tissue through exercise (ACTIBATE) in young adults: rationale, design and methodology. Contemp Clin Trials $45: 416-425$

16. Sanchez-Delgado G, Alcantara JMA, Ortiz-Alvarez L, Xu H, Martinez-Tellez B, Labayen I, Ruiz JR (2017) Reliability of resting metabolic rate measurements in young adults: impact of methods for data analysis. Clin Nutr 37:1618-1624. https://doi.org/10.1016/ j.clnu.2017.07.026

17. Schindelin J, Arganda-Carreras I, Frise E, Kaynig V, Longair M, Pietzsch T, Preibisch S, Rueden C, Saalfeld S, Schmid B, Tinevez JY,
White DJ, Hartenstein V, Eliceiri K, Tomancak P, Cardona A (2012) Fiji: an open-source platform for biological-image analysis. Nat Methods 9:676-682

18. Leitner BP, Huang S, Brychta RJ, Duckworth CJ, Baskin AS, McGehee S, Tal I, Dieckmann W, Gupta G, Kolodny GM, Pacak K, Herscovitch P, Cypess AM, Chen KY (2017) Mapping of human brown adipose tissue in lean and obese young men. Proc Natl Acad Sci U S A 114:8649-8654

19. Gifford A, Towse TF, Walker RC, Avison MJ, Welch EB (2016) Characterizing active and inactive brown adipose tissue in adult humans using PET-CT and MR imaging. Am J Physiol Endocrinol Metab 311:E95-E104

20. Cole TJ, Flegal KM, Nicholls D, Jackson AA (2007) Body mass index cut offs to define thinness in children and adolescents: international survey. Bmj 335:194-194

21. Aubrey J, Esfandiari N, Baracos VE, Buteau FA, Frenette J, Putman CT, Mazurak VC (2014) Measurement of skeletal muscle radiation attenuation and basis of its biological variation. Acta Physiol 210:489-497

22. Blondin DP, Labbé SM, Noll C et al (2015) Selective impairment of glucose but not fatty acid or oxidative metabolism in brown adipose tissue of subjects with type 2 diabetes. Diabetes 64:2388-2397

23. Chechi K, van Marken Lichtenbelt WD, Richard D (2017) Brown and beige adipose tissues: phenotype and metabolic potential in mice and men. J Appl Physiol 8711:482-496. https://doi.org/10.1152/ japplphysiol.00021.2017

24. Cannon B, Nedergaard J (2004) Brown adipose tissue: function and physiological significance. Physiol Rev 84:277-359

25. Cypess AM, White AP, Vernochet C, Schulz TJ, Xue R, Sass CA, Huang TL, Roberts-Toler C, Weiner LS, Sze C, Chacko AT, Deschamps LN, Herder LM, Truchan N, Glasgow AL, Holman AR, Gavrila A, Hasselgren PO, Mori MA, Molla M, Tseng YH (2013) Anatomical localization, gene expression profiling and functional characterization of adult human neck brown fat. Nat Med 19:635-639

26. Ruiz JR, Martinez-Tellez B, Sanchez-Delgado G, Osuna-Prieto FJ, Rensen PCN, Boon MR (2018) Role of human brown fat in obesity, metabolism and cardiovascular disease: strategies to turn up the heat. Prog Cardiovasc Dis 61:232-245

27. Peirce V, Carobbio S, Vidal-Puig A (2014) The different shades of fat. Nature 510:76-83

28. Chen YI, Cypess AM, Sass CA, Brownell AL, Jokivarsi KT, Kahn CR, Kwong KK (2012) Anatomical and functional assessment of brown adipose tissue by magnetic resonance imaging. Obesity 20:1519-1526

29. Hoeke G, Kooijman S, Boon MR, Rensen PCN, Berbée JFP (2016) Role of brown fat in lipoprotein metabolism and atherosclerosis. Circ Res 118:173-182

30. Gordon K, Blondin DP, Friesen BJ et al (2019) Seven days of cold acclimation substantially reduces shivering intensity and increases non-shivering thermogenesis in adult humans. J Appl Physiol. https:// doi.org/10.1152/japplphysiol.01133.2018

Publisher's Note. Springer Nature remains neutral with regard to jurisdictional claims in published maps and institutional affiliations. 